\title{
Modern Ethno-Economic Processes in the Sayano-Altai Region: Continuity, Universality, and Multifunctionalism
}

\author{
V.K. Sevek ${ }^{1, *}$ R.S. Taybyl ${ }^{2}$ Kh.B. Badarchi ${ }^{3}$ R.M. Sevek ${ }^{1}$
}

\author{
${ }^{1}$ Tuvan state university, Kyzyl, Russia \\ ${ }^{2}$ Tuvan Institute of Humanitarian and Socio-Applied Studies, Kyzyl, Russia \\ ${ }^{3}$ Tuvinian Institute for Exploration of Natural Resources of Siberian Branch of the Russian Academy of Sciences, Kyzyl, \\ Russia \\ *Corresponding author. Email: vsevek@mail.ru
}

\begin{abstract}
The relevance and scientific significance of the research are determined both by the scientific and ethnoeconomic factors that study the peculiarities of the economic activity of the Sayano-Altai region ethnic groups, in particular, the Republic of Tyva and Western Mongolia. The scientific novelty of the study lies in the determining of the role of the ethnic economy in the food supply, employment, population income generation through the development of methodological principles for the improvement of ethno-economic processes in the Sayano-Altai region. The practical significance of the study consists in the necessity to develop the scientifically sound approaches to the construction of the intergovernmental system of economic education, institutions, and support infrastructure. The results of the study propose models and methods of effective ethno-economic business activities inherent for the Sayano-Altai region.
\end{abstract}

Keywords: ethnic economy, traditional economy, Sayano-Altai region, intercultural interaction, entrepreneurship

\section{NTRODUCTION}

The Central Asian region, in terms of the modern theory of the competitiveness of economic systems, appears to be a region with low economic growth, low factor productivity and the inability of companies to compete successfully in international markets. However, given the globalization of the economy, the region is of great interest to both regional and (legally) distant countries in the context of the project "One Belt - One Way." At stake in the game in this region are geopolitical power, access to potentially immense wealth, the achievement of religious and national goals, and security in a variety of its aspects. Among all of the above aspects, the ethnocultural side plays a significant role.

The eastern part of the Central Asian region is distinguished by the Sayano-Altai subregion, which includes the peoples of its Russian part $(62 \%$ of the subregion) - Altaians, Shorians, Khakass people, Tuvans and Western Buryats, peoples of the Western Mongolian part (29\%) - Khalkha people, Torguts, Derbets, Khoshuts, Bayats, Olets, Altain-Uriyankhai, Zakhchins, Sartuuls, minor ethnic Tuvan groups (Uriyankhs, Darkhats, Tsaatans) and Kazakhs. The western part of the Altai mountain range -the Xinjiang-Uighur autonomous region of PRC represents $4 \%$ of the subregion (Jungar part) and part of East Kazakhstan -5\% (Figure 1).

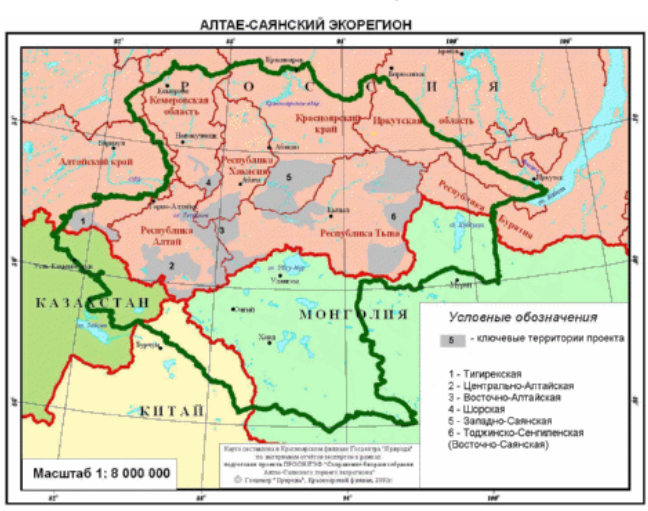

Figure 1 The map of the Sayano-Altai region [1].

Tuva is located in the center of the Sayano-Altai subregion. The historical nomadic civilization of the Sayano-Altai people determines the traditional forms of economic activity such as livestock breeding on pastures combined with natural and small-scale forms of production: artisanal crafts, home-based work and other extensive forms of employment. Grain cultivation is also an ancient economic activity of pastoralists, but it is considered to be ancillary. 
The study aims to propose methodological principles for the improvement of ethno-economic processes in the Sayano-Altai region based on methods and models of effective use of the potential of ethnic households in the socio-economic development, as well as to reveal the role of the ethnic economy in the food supply, employment, and income generation.

The following objectives are proposed to achieve the goals above:

1. To carry out a comparative analysis of farming methods in traditional industries of different ethnic groups of the region in the historical and geographical aspects:

- to define climatic features of the Sayano-Altai region in terms of opportunities and limitations for economic activity;

- to study the process of ethnic economy formation from the historical and civilizational sides, including the influence of the 20th-century events and social phenomena;

- to specify particular technologies and traditional technical means of the sectors of different ethnic economies within the region and their perceptivity to technological achievements of the epochs of mechanization, automation, and informatization;

- to study relevant industry structures of the gross products of the Sayano-Altai region's modern administrative territories, to carry out the comparative analysis and typological classification of ethnic economies based on branch specialization.

2. To describe the mental pattern of the economic behavior of the representatives of different ethnic groups in the region, including the comparison with those of settled ethnicities:

-to revealusing the survey method of the representatives of different ethnic economies:

- auto-stereotypes regarding their knowledge and abilities to successful economic activity;

- public sentiments on existing institutes and the infrastructure of traditional industries support and development;

-value orientations in decision-making;

- understanding of typical economic tasks and abilities to solve them.

- to define similarities and differences between mental models of the economic behavior of nomadic and settled ethnicities.

3. To carry out an extended analysis of the economic efficiency of standard ethnic households in terms of modern scientific micro- and regional economics methods.

4. To carry out a comprehensive analysis of the economic and ethno-social consequences of the ethno-economic relations within the Sayano-Altai region in conditions of globalization and in the context of the project "One Belt One Way."

5. To develop scientifically sound approaches to the construction of an intergovernmental system of economic education, institutions and support infrastructure for the ethnic economies of the Sayano-Altai region.

The object of the study is ethno-economic households of the Sayano-Altai region.

The subject of the study is economic behavior that occurs in the process of ethno-economic activity in the SayanoAltai region.

\section{RESEARCH METHODS}

The methodology of the study is based on the principles of economic-historical approach and objectivity in revealing the methods of ethnic housekeeping and the peculiarities of technology and traditional technical means of the Sayano-Altai region ethnic groups. An integrated approach, that is based on the economic, ethnographic, geographical, historical, cultural, ethnopsychological and other data, is proposed to research the economic and ethno-social consequences of the ethno-economic relations within the Sayano-Altai region in conditions of globalization. The methods of comparative, cluster, correlational, typological analyses and synthesis of scientific results of the research are used to assess the economic efficiency of standard ethnic households in terms of modern scientific micro- and regional economics methods and to develop the scientifically sound approaches to the construction of an intergovernmental system of economic education, institutions and support infrastructure for the ethnic economies of the Sayano-Altai region. We use mathematical and general scientific methods of economic research, such as analysis, induction and deduction, comparison and generalization to solve some of the tasks. The methods above allow identifying the specific peculiarities of the national character and mentality of the Sayano-Altai people, to study the role of the economy, culture and mundanity and to propose scientifically sound ways of developing the region.

\section{REVIEW OF LITERATURE}

Ethno-economics as a science that studies relationships and interactions and influence of traditions, customs, culture, psychology, ideology, religious views of different ethnicities on the character and level of development of factor productivity and production relations, originated abroad in the 1990s as an independent scientific direction 
[2]. It aims to show the ethnic specificity of human economic behavior and to reveal the apparent propensity of ethnicities towards certain economic activities from generation to generation. Today, when a wide range of sources describing the relations in the ethnic economies (or ethnos and economy) have become available to researchers, the necessity to take into account the interethnic factor in creating favorable conditions for sustainable development of regional economies becomes obvious.

Modern national and foreign researches in the field of ethno-economics, published in recent years, are represented by ethnoculturally diverse works describing social mechanisms of the economic life of different ethnic groups. The studies highlight the conceptual factors of economic centralization (single market), based on the impact of cultural and political specificity, natural and climatic conditions, types of households and peculiarities of national character on the economic specialization. In order to interpret the role of the ethno-economy in the socio-economic development of inter-ethnic communities, social stability and economic productivity, researchers distinguish traditional and innovative types of ethnic entrepreneurship. Studies, related to the development of inter-ethnic communities through the development of methodological principles for the improvement of ethnoeconomic processes in the Sayano-Altai region, should be carried out based on methods and models of effective use of the potential of ethnic households in the development of socio-economic systems, as well as on the revealing of the role of ethno-economy in the food supply, employment and income generation.

The methodological principles of an integrated approach to the study of the nature of historical development of Central Asian nomads along with identification of the common patterns in ethnic activities, determined bysocial, demographic, environmental, and economic factors, were described in S.I. Weinstein's writings "The World of Central Asian Nomads" (1991) and "Nomads of South Siberia: The Pastoral Economies of Tuva" (1980). Among English-language scientific publications there are the works of B. Purzitskiy "Spirit masters, ritual cairns, and the adaptive religious system in Tyva" (2010), "Tyva Republic (Shamanism, Totemism, Animism: Religion Variables» (2013), «Ritual Behavior and Trust in the Tyva Republic» (2013), «Tyvan Cher Eezi and the Socioecological Constraints of Supernatural Agents' Minds» (2011), etc., aiming to describe the spiritual, applied culture, religion and socioecological relations of ethnos "Tyva".

It is also worth to note B. Donahoe 's works "On the creation of indigenous subjects in the Russian Federation"
(2011), "Who Owns the Taiga? Inclusive vs. Exclusive Senses of Property among the Tozhu and Tofa of Southern Siberia"(2006),"A line in the Sayans: history and divergent interpretations of property among the Tozhu and Tofa of South Siberia"(2004), where he studied the annexation of Central Asian ethnicities to Russia at different periods, the attitude of Tuvans to nature of the native land and their perception of the environment. Paul Hooper, with his "Early report from Tuva" (2013), "Social and economic underpinnings of human biodemography" (2014), contributed to the historiography and research of Tuvans' biodemography.

The essential sources of study of traditions, customs, culture, psychology and religious views of ethnic groups of the subregion are the studies of Tuvan scientists, represented by the works of M.B. Kenin-Lopsan "Traditional culture of Tuvans" (2006), E.V. Aiyzhy "Rituals and Customs Related to the Cults of Nature of the Tuvans of the Republic of Tyva of the Russian Federation, China and Mongolia at the beginning of the XXI century (Comparative aspect)"(2013),"Influence of ethnic Tuvans of north-western Mongolia on traditional nature use" (2015), A.K. Kuzhuget "Spectacular game elements in the cult rituals of Tuvans" (2002), "Spiritual culture of Tuvans" (2006); O.M. Khomushku "Religion in the Culture of Sayano-Altai Peoples" (2005); N.O. Tovuu "Socio-psychological researches: ethnos Tyva at the turn of the century (XX-XXI centuries)" (2009); V.K. Darzhaa "Traditional men activities of Tuvans" (2013), et al.

Undoubtedly, the laboratory of "nomadic" civilizations of the Tuvan State University, which introduced a series of scientific and educational publications, played an important role in studying of the ethnocultural traditions of the peoples of Central Asia. Among the works, the research papers of Abayev N.V., Arakchaa L.K., Feldman V.R. "The ethnoecological culture of Central Asian people in the context of paleoanthropological researches (on materials of archeological sites of Tuva)" (2005) and "Civilizational geopolitics and ethnocultural traditions of the people of Central Asia and the Altaian-Baykal region" (2006) hould be noted.

Studies close to the declared topic include the monograph of V.S. Panikarova [3]. The monograph presents the results of the study of the regularities in the ethnoeconomy development in the conditions of modernization within the framework of modern synergistic, reproductive and evolutionary approaches to the regional development of the Republic of Khakassia, including agrarian economy, traditional environmental management, folk arts and crafts.

Taking to account an important role of the analysis of the relationship between ethnic and socio-economic processes 
region based on nomadic civilization, various cultural and

and of the study of national peculiarities of economic behavior in ethnoeconomics, the dissertations of $\mathrm{B}$. Amarsanaa and B.A. Dongak, defended for the degrees of Candidate of Economic Sciences at Saint-Petersburg State Economic University in 2015 and 2016, respectively, seems to be interesting within the framework of our study $[4,5]$. B. Amarsanaa justifies the following positions as a novelty of the study: ethnocultural factors in the development of Mongolian corporations have been identified; the ethnic features of Mongolian companies' corporate governance in the process of decision-making are defined; theoretical and methodological foundations of the transformation of the models of organizational culture in fluencing the national model of corporate governance are disclosed. B.A. Dongak's thesis on "Formation and development of ethnic clusters of entrepreneurship (on the example of the Republic of Tyva)" is the first work, studying the theoretical and methodological bases of formation of ethnic clusters with regard to the development of entrepreneurial activities in the Republic of Tyva. The methodology of research of the mentioned works will contribute to the determination of types of ethnic entrepreneurial activities within the regions of interest and the determination of places to locate enterprises for processing livestock products given the national organizational model and transport accessibility. Contemporary studies in the field of ethno-economics, including the scope and structure of ethno-economics, entrepreneurial potential, ethno-tourism, networking relationship, transformational changes in the regional community, ethno-management, patterns of economic behavior and other aspects, are developed in the works [6, $7,8,9,10,11,12,13,14,15,16,17,18]$. Thus, in the scientific literature, traditional culture and housekeeping within the frame of ethnic economy, in general, have been reflected. However, specific aspects of the formation of ethno-economics from the historical and civilizational sides, perceptivity to technological achievements of the epochs of mechanization, automation and informatization, economic efficiency of standard ethnic households in terms of modern scientific micro- and regional economics methods, understanding of the economic and ethno-social consequences of the ethno-economic relations within the Sayano-Altai region in the context of globalization are still subject to systematization as well as to comprehensive generalization of the research.

\section{RESULTS OF THE RESEARCH}

From the historical and economic points of view, the intensive interaction of the peoples of the Sayano-Altai religious traditions of ethnic groups living in the area have led to a common cultural identity, with some local ethnic peculiarities. The interrelations and interlinkages of traditions, customs, culture, psychology, and the ideology of nomadic lifestyles led to the identical traditional herding-dominated economy. It can be seen in the adaptation of different nations and nationalities to ethnic processes rather than to economic processes, where the root cause is ethnic features, but not economic phenomena. Therefore, it is necessary at the present stage to create conditions for the development of entrepreneurial activities of ethnic households and entities, the production and sale of the products traditional to ethnos on a mass scale as well as to introduce new products, which are close to the nomad lifestyle, for example, Ethnotourism. The formation of new ethnic entities with innovative technologies such as mechanization, automation, and informatization, together with traditional technical means, does not lead to the loss of the philosophical concept of Central Asian traditional nomad culture but contributes to the receptivity of the ethno-economy of the region to the entrepreneurship.

It is proposed to study comprehensively the autostereotypes regarding the knowledge and abilities of the representatives of different ethnic groups within the region to successful economic activity, their value orientations in decision-making, and other aspects related to traditions, perception of the world by Central Asian people (in particular of the Republic of Tuva and Mongolia), their transformation in the modern world to determine the mental pattern of their economic behavior, including the comparison with those of settled ethnicities.

Historically established economic activity of the peoples of Sayano-Altai is particularly evident in the Republic of Tyva and Western Mongolia, where the traditional live stock breeding on pastures is still kept in the original form with migrations four times a year, while for Altaians, Khakass people, Buryats, and Kazakhs the nomadic way of life is becoming a part of the past. Summer, autumn, winter, and spring migrations developed for centuries are related to the restoration of grazing lands of livestock. These methods of traditional economy of the Sayano-Altai people all owed to develop unique ethno-regional traditional technologies of production of material culture such as traditional housing, everyday clothes, clothing for hunting and fishing, as well as a traditional system of orientation. The main type of dwelling of TurkicMongolian peoples of Central Asia (Tuvans, Mongols) is a yurt. At the same time, hunters-reindeer herders TuvansTodjins (Eastern part of the Republic of Tyva) and Mongolian Darkhats and Tsaatans (North-West Mongolia) 
interactions with nature, technology, and social institutions at the age of globalization.

in summer- with birchbark or larch-bark. The uniqueness of these types of housing is that traditional dwellings remained original even in the 21 st century, despite the modern transformational processes, though nowadays it is possible to observe modern facilities inside or outside yurt (like solar stations that allow using modern technologies of communication).

Arats-livestock breeders have perfectly learned animal habits, their need for pastures, feed, behavior depending on the seasons of the year, anatomy and physiology of animals. It is evident that ethno-economic researches are among the needed and practical tasks, the study of ethnic characteristics of economic behavior provides an opportunity to find the right and organic forms of employment to ensure the effective use of human potential. Based on the importance of ethno-economy in the economic activities of Sayano-Altai peoples, it is necessary to formulate its institutions in terms of a market economy. Therefore, in addition to problems of economico-legal and administrative nature, ethnoeconomies should be studied from the different fields of science as well: economics, ethnography, historicalcultural, geographical, ethnic psychology, et al.

The study of the ethno-cultural traditions and traditional economy of the Sayan-Altai peoples, in particular, of Tuvans, is considered on the one hand as a resource to increase the economic stability of the subject of the Russian Federation, on the other hand -as a mean for socio-economic development forecasting, for public regulation of the economy and of the socio-economic processes. $46 \%$ of Tuvans live in rural areas and $10 \%$ work in the agro-industrial sector. As of 2019,livestock breeding represents $85 \%$ of the Tuvan agricultural sector, crop production - $15 \%$ (Strategy of agricultural development of the Republic of Tyva for the period up to 2030). $60 \%$ of the total number of livestock of all types (cows, sheep, goats, horses, yaks, camels, and deer) belong to individual households. All categories of Tuvan farms, households, entities engaged in livestock breeding practice traditional breeding on pastures.

On the other hand, the traditional sector does not meet the criteria of the market economy due to the underdeveloped sales markets for livestock products. In this regard, it is necessary to develop theoretical and methodological approaches for the production and sale of organic and ecofriendly products of ethnic households. The study of traditional livestock breeding in Tuva let to identify common and local features of nomadic economy in general in the mountain-steppe region of the Sayano-Altai Highlands, which could give answers on the human

\section{CONCLUSIONS}

The scientific significance of the study is supposed to be in the disclosure of the essence of ethno-economic potential as a set of economic resources of ethnocultural activity of the Sayano-Altai region, capable of becoming its opportunities, means, and tools of achievement of the socio-economic development of the subregion as a whole and its different parts.

The practical significance of the study lies in the development of a scientifically sound approach to the construction of an intergovernmental system of economic education, institutions and infrastructure to support ethnoeconomies in the Sayano-Altai region.

\section{ACKNOWLEDGMENT}

The study was carried out with the financial support of the RFFI 19-010-00831 A grant.

\section{REFERENCES}

[1] Archeology, Ethnography and ecology of Siberia [Elektr. resource], Kemerovo state University. URL: http://museum.kemsu.ru/altaisain.html

[2] Popkov Y. V., E. A. controlling the ethnical economy and the economy: a synergy of possibilities, EKO. - 2018. - No. 5.

[3] Panikarova V. S. Ethnoeconomics of the region: trends and prospects,Abakan: Publishing HOUSE of the Khakass state University. N. F. Katanova", 2012. - 222 p.

[4] Amarsanaa B. Formation of a national model of corporate governance management in the conditions of formation and development of organizational culture (on the example of corporations in Mongolia): autoref. dis... Cand. Econ. science / B. C. Polikarpov, SPb., 2015, 17 p.

[5] Dongak B. A. Formation and development of ethnic clusters of entrepreneurship (on the example of the Republic of Tuva): Dis.Cand. Econ. science: 08.00.05. / B. A. Dongak, SPb., 2016, 155 p. 
[13] Kadukova S. A., O. A. Persian ethnical economy in action: the experience of Tuva and Altai, EKO. 2018, No. 5.

[14] Mukha V. N. et al. Ethnic factor in the development of the economy of the Krasnodar territory, Bulletin of the Adygeya state University. Series 1: regional Studies: philosophy, history, sociology, law, political science, cultural studies, 2018, No. 1.

[15] Pavlov K. V. Ethnomanagement as an integral part of ethnoeconomics. Scientific notes of the Crimean Federal University. V. I. Vernadsky, Economics and management, 2015, No. 3.

[16] Persian O. A., Kadukova S. A. Traditional culture and the ethnical economy in the system of the determinants of transformation of the regional community, news of higher educational institutions. Sociology. Economy. Politics, 2018, No.2.

[17] Surnina N. M., Pechura O. V. Ethnoeconomics of the territory: synthesized paradigm, quantitative characteristics and problems of management, Municipality: economy and management, 2012, No. 1.

[18] Ugryumova M. N., Pikovsky A. A. Autochthonous and allochthonous regional ethnoeconomics, Russian entrepreneurship, 2012, No.4.
[12] Kolesnikov Yu. s., J. D. Darmilov Traditional economic practices of peoples of the North Caucasus and the present, Bulletin of the Adygeya state University. Series 5: Economics, 2015, No.4. 